THOMASON, PETER (1945), "Old Age: A Burden or a Joy?" Manchester.

29. FRIENDS' RELIEF SERVICE (1945), "Hostels for Old People," London.

RACKSTRAW, MARJORIE (1944), "An Old People's Hostel," reprint from Social Work, N.C.S.S., London.

30. See note 25.

3I. Lancet (March 4, I944).

32. See note 25.

33. The Times (Feb. 3, I946), etc.

34. Lancet (I946), I, 595.

35. BANKS, A. LESLIE (I945), "The Care of the Infirm and the LongStay Patient," in Monthly Bulletin of the Ministry of Health and Emergency Public Health Service, 4, $112-118$.

Idem (Oct. 6, I945), "Geriatrics: A New Branch of Medicine," in Pharm. J., 158 .

CAHILL, JOHN (Feb. 27, 1946), "The Last Stage of All: Hospital Care of the Aged," in Med. Press and Circular.

CREW, F. A. E. (1946), v. supra, note I.
HOWELL, TREVOR H. (I944), "Old Age: Some Practical Points i

Geriatrics," London.
LEWIS, A. J., and GOLDSCHMIDT, H. (July-Oct. I943), "Social Causes of Admission to a Mental Hospital for the Aged," in Socio logical Review, 86-98.

WALKER, J. V. (I944), "Annual Report of the Medical Officer of Health," Ramsgate, 8 .

See also: The Times (Feb. 9, I946); Brit. Med. J. (Mar. 2, 1946) Lancet (Mar. 9, I946), etc.

36. SMITH, JOHN (1666), "King Solomon's Portraiture of Old Age," I 66 " 37. BELLERS, JOHN (I695), "Proposals for Raising a Colledge of Industry of all useful Trades and Husbandry," 6, London.

38. See STIEGLITZ, E. J. (June-July I944), "Senescence and Industry, 웅 in Scientific Monthly.

39. BOSSARD, J. H. S. (1934), "Social Change and Social Problems, $\frac{(\rho)}{T}$ chap. xv.

40. GUMPERT, MARTIN (I944), "You are Younger than You Think, $\mathbb{D}$ New York.

4I. PIERSOL, G. M., and BORTZ, E. L. (1939), "The ageing processôn a medical-social problem," Ann.Inst. Med., 12, 964 .

\title{
INFANTILE ECZEMA
}

\author{
By I. R. MARre, M.R.C.S., L.R.C.P. \\ (Skin Physician to the Acton and Evelina Hospitals)
}

This is a common disorder, which embraces a number of different conditions, and in my experience can most reasonably be divided up into four unequal groups. These are:

a. Atopic or allergic group.

$b$. Seborrhoeic group.

c. Ichthyotic or Xerodermic group.

d. Infected group.

of which the first two groups comprise by far the largest number of cases.

I have found it useful to attempt to place each case in its special group, as treatment and prognosis vary a good deal. Occasionally one does see p stients who show characteristics of more than one group, but this is by no means usual.

\section{a. Atopic or Allergic Group}

This is the largest group and consists of those children with true infantile eczema. There is commonly a history of family allergy such as asthma, hay fever or eczema, and really severe cases can give a history of allergy in the families of both parents.

The child is well at birth but shows first signs of skin trouble when about eight to twelve weeks old. This consists of a papular, papulo-vesicular or vesicular eruption involving the face and body, with a special tendency to affect the limb flexures. Typically a patch consists of an ill-defined erythema, closely set with vesicles, which is intensely pruritic and the child makes frantic efforts to scratch. Trauma leads to removal of the tops of the vesicles and to the exposure of a raw weeping surface which becomes crusted with dried serum. Persistent rubbing and scratching lead to an extension of the inflammation with infiltration and fissuring, and the child finally presents an excoriated, wizened, woebegone appearance that is characteristic. The disease is persistent and chronic, and prone to relapses and recurrences ${ }_{i}^{\circ}$ but there is often a spontaneous improvement of healing towards the end of the second year.

It is in this group that eczematous infants may exchange their skin condition for asthma or haye fever as they get older, and they may go on to the chronic atopic eczema of later childhood, adoles $\vec{\varphi}$ cence and adult life, with thickening and lichenffit cation of the skin flexures. It is in this group, too? that the eczematous infant will give positive slaino tests to proteins more frequently than in the others groups or than in normal children, but in my viewo this sensitivity is not specific, since I have founकै that the skin in infantile eczema will tend to show a positive result to a large number of protein skin $\overrightarrow{\vec{b}}$ tests, and that the withdrawal of these proteins seems to make little difference to the course of the disease. Occasionally one will find a child benefie markedly by the withdrawal of the protein too which it is especially sensitive. Substances which. commonly give positive skin tests in these infantso are Egg (particularly Egg-white), Milk, Wheat and Barley.

\section{Treatment}

The importance of local treatment is hardly tot be overestimated, and all efforts must be made toe protect the infant's skin from the environmentaf changes to which they seem unable to adjust them selves in their journey from the uterus to the outside world.

The infant must not be exposed to direct sun? shine, strong winds or severe changes of temo perature, and the temperature of the room should be kept evenly about $70^{\circ} \mathrm{F}$. Clothing should be loose, light and soft, and wool should never be worn next to the skin; smooth cotton garments should be used in preference. 
The child must be kept as clean as possible, but soap must never be used. A tepid bran or oatmeal bath may be given every two or three days, but should not be persisted with if it should exacerbate the condition. Bran or oatmeal baths are prepared by filling a muslin or cheesecloth bag with about I lb. of bran or oatmeal, and allowing the hot water to run through the bag first, and then complete the filling with water at a suitable temperature. The bag may be left in the bath. Crusts and scales may also be removed by the application of a Starch and Boric poultice. This is made by adding one teaspoonful of boric powder to a tablespoonful of powdered starch, and mixing with cold water to a thin paste. Then boiling water is poured on until a thick jelly is formed which is allowed to cool. This should be spread thickly upon lint and applied directly to the crusted part, the poultice being changed every half hour until all the crusts are removed.

Should baths not be tolerated, further cleansing may be carried out with olive oil or liquid paraffin.

Local applications to the skin depend almost entirely on the phase of the disease, and the following prescriptions are given in order, but it is often possible to miss one or two steps, if the condition subsides rapidly.

Acute weeping state. This is best treated with wet compresses such as Boric Acid or Lead Lotions. Boric Acid compresses are made by adding one teaspoonful of Boric Acid to a tumblerful of hot water and allowing to cool. Lead Lotion compresses are made by adding one drachm of Liquor Plumbi subacetate fort. To each pint of cold tap water. White lint cut to size and shape of the affected parts should be used and dipped into the prepared lotion, lightly squeezed and applied. These compresses should not be allowed to dry on, but should be re-dipped and re-applied before they dry. After two or three days the skin is usually ready for the next application.

\section{Calamine Liniment.}

$\mathrm{B}_{\mathrm{k}} \quad$ Calamine prep. ..................

Zinc Oxide ......................

Liquor Calcis.................... 32

Ol. Olivae (or Ol. Arachis) ...........ad $\xi \mathrm{I}$

or if it is fairly dry the infant could be put straight on to Cremor Zinci B.P.C. to which I per cent Ichthyol is added. Finally when the skin reaches the dry scaly chronic phase, the following paste is useful:

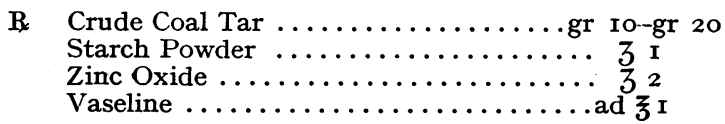

This should be applied thickly on closely woven linen or cotton dressings, and changed twice daily.
For the face a mask may be used, with holes cut for eyes, nose and mouth. If the tar proves $\varrho$ unsuitable, it may be replaced with Ichthyol. $\frac{\$}{\infty}$ (Exposure to sunlight is forbidden when $\operatorname{tar}$ is $\frac{\varrho}{c}$ used, as it is a photosensitising agent.)

Scratching and traumatisation must be pre- $\overrightarrow{\bar{F}}$ vented, and the application of wooden or stout $\overline{0}$ cardboard splints to the arms is invaluable. 항 Tying of hands and even feet to the cot may be $\frac{\bar{m}}{\bar{s}}$ necessary, and it is remarkable how well infants $\stackrel{\Phi}{\circ}$ tolerate this.

Sedatives should be used where necessary, and के Syrup Chloral B.P.C. I drachm can be given two $\vec{\circ}$ or three times daily, or Phenobarbitone gr $\frac{1}{6}-\frac{1}{4} \overrightarrow{\vec{\omega}}$ can be given at night.

The patient shows a variation in type of eruption as he gets older. The infant exhibits an exudative 3 form, whereas a more thickened lichenified type appears as the patient grows up, together with a i greater predilection for the flexures. A typical $\overrightarrow{0}$ picture in an older patient will show a chronic $\vec{\bullet}$ lichenified eruption of the cubital spaces, possibly $\bullet$ the wrists, and the popliteal spaces, together with 은 an occasional patch around the neck. For this condition the last Crude Coal Tar paste is useful, $\subseteq$ or the following cream:

R Crude Coal Tar .................. gr ro

Cremor Zinci B.P.C. ..............ad $\xi^{1}$

Where the Coal Tar is not tolerated, replacement. by Ichthyol is beneficial. Large doses of Vitamin A by mouth (20,000-30,000 units daily) sometimes seems to effect an improvement in the skin condition.

\section{b. Seborrhoeic Group}

It is my experience that this group shows signs earlier than the atopic group, and is often seen only two or three weeks after birth with the condition already well established.

The seborrhoeic group exhibits typically a "milk crust" consisting of a thick scaly crust involving much of the vertex, which is usually fairly circumscribed. The face, back and chest are affected by a scaly eruption on an inflammatory base, which tends to occur in rather sharply circumscribed $\frac{7}{0}$ patches, and does not show the vesiculation of the atopic type. It is not so pruritic, and responds o much more easily to treatment. In these cases I make a point of examining the parents, and often find that one or both have a marked degreee of pityriasis capitis, which it is well to treat at the same time.

\section{Treatment}

Local treatment here is more important even than in the atopic type, and the response is usually 
immediate. The affected part of the scalp should be gently rubbed with the following ointment once or twice daily, and the scalp washed each week with water and a good castile coap:

B. Ac. Salicyl....................gr 5

Sulph. Precip. .................gr 5

Adeps Benzoinat..$\ldots \ldots \ldots \ldots \ldots \ldots \ldots$ ad 35

This soon loosens the seborrhoeic crust, which disappears within a week or two.

In the acute phase, the body eruption will benefit from:

B $\quad$ Sulph. Precip. . . . . . . . . . . . . . . gr $2 \frac{1}{2}$

Tr. Quillaiae........................ Io

Lot. Calamine .................... 3 I

applied for a few days, and followed by:

R Ichthyol ................... Io

Ol. Olivae (or Arachis) $\ldots \ldots \ldots \ldots \ldots \ldots, 3_{2}$

Cremor Zinci B.P.C. ..............ad $\xi^{1}$

and finally the olive oil may be omitted, as in

R Ichthyol .................... Io

Cremor Zinci B.P.C. ................ ad $\xi$

These measures usually suffice to bring about a cure. Sedatives and splints are not necessary, and the methods of cleansing are similar to those mentioned in the Atopic group. Woollen garments next to the affected parts are to be avoided, and fresh air is to be encouraged.

\section{c. Ichthyotic Group}

Ichthyosis or Xerodermia (mild Ichthyosis) is a congenital condition of the skin, often with a marked familial history, appearing some time after birth. The mild condition usually shows itself between I and 2 years old, and the severe condition within the first few months. It consists of a dryness and harshness of the skin, where the natural lines and furrows are greatly exaggerated, due to a thickening of the horny layer of the epidermis, and diminution of the skin secretions. It is usually present on the extensor aspects of arms and legs, but may be more symmetrically widespread, giving rise to a scaly fish-skin appearance. The flexures are usually spared.

The Ichthyotic skin is especially affected by changes of temperature and by exposure, and is invariably worse in winter. Eczematous changes occur easily in the dry and sensitive skin, and the vicious circle of pruritus and increasing eczema is set up; so that a severely eczematised case of ichthyosis may resemble an atopic type very closely, particularly as asthma is sometimes found in association with ichthyosis. Diagnosis is not difficult, as the underlying ichthyosis can usually be distinguished, but is in any case obvious when the eczema subsides under treatment. The strongly familial history, later age of onset, and comparative freedom of the flexures all assist in the diagnosis, which is important to make as Ichthyosis persists throughout life.

\section{Treatment}

Large doses of Vitamin A, as in the Atopic type, are of great benefit in this condition, and Thyroid gland is sometimes of help. I have found the injection of crude liver extract once or twice weekly of particular assistance in resistant cases.

Local treatment for the eczematous ichthyotic is much the same as for the atopic type, except that drying lotions should not be used. The Calamine linimint is useful, as is the Zinc cream with Ichthyol, or Zinc cream alone. Crusts and debris should be removed by the methods already mentioned, and bran used in the bath.

\section{d. Infected Group}

This is secondary to some primary infection or infestation, such as impetigo, furunculosis, otitis, scabies or pediculosis. Infection and trauma lead to scaly, vesicular or pustular lesions which spread peripherally, to become rather circumscribeds asymmetrical plaques, and the peripheral epidermis is undermined with a thin purulent edge. The child looks and is ill, with a raised temperature and a lymphadenitis. Pruritus is present, and search should be made for the primary cause; bearing in mind particularly the acarus in its burrow, and the pediculus. Disinfestation should be carried out where necessary.

\section{Treatment}

Immersion in baths of $I / 8,000$ to $x / I 0,000$ Potassium Permanganate is useful, together with full doses of Sulphadiazine or Sulphathiazole by mouth. It is my practice never to use the sulphonamides locally because of their extraordinary 윽 sensitising powers. If the predominant organism $\rightarrow$ is penicillin sensitive, spraying with penicillin solution three times daily clears up the septic condition quickly, or the body may be painted with a one per cent aqueous solution of gentian $N$ violet. After infection has been eradicated a final $N_{\omega}$ soothing dressing of Zinc cream or Calamine liniment is all that is necessary. Foci of infection 0 should be eliminated.

Any or all of the first three groups may become $\stackrel{\oplus}{+}$ infected, in which case the infection is treated 0 first, followed by the treatment recommended for $\underset{\mathbb{D}}{\vec{D}}$ each special group. 


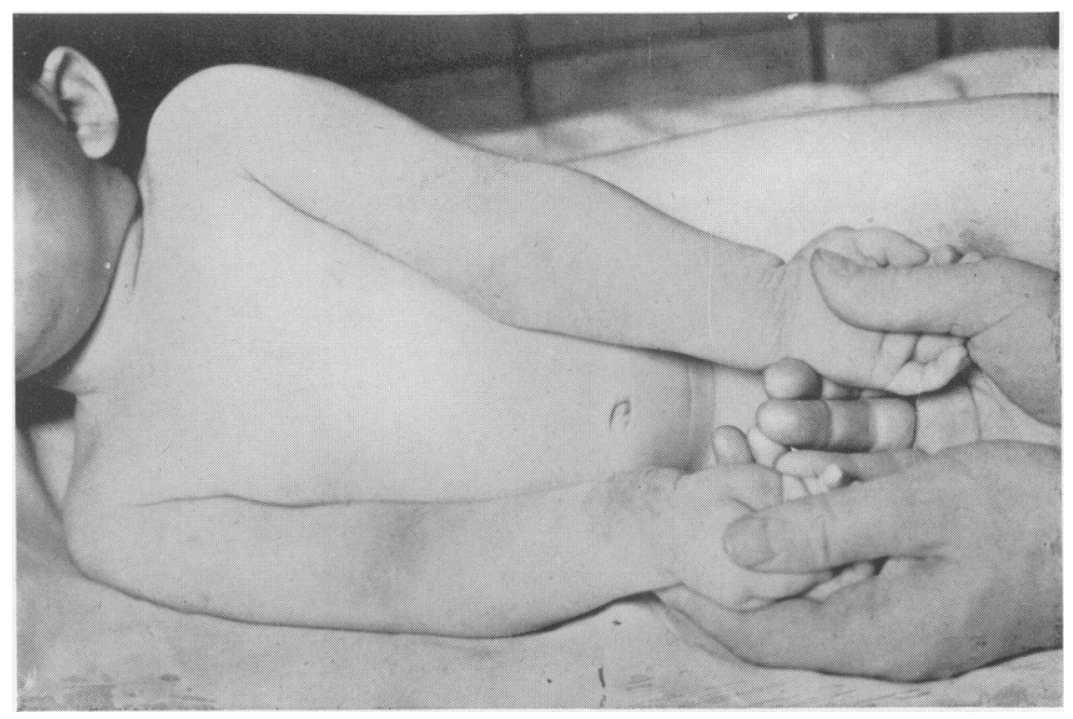

Atopic Type-Involvement of Arm Flexures and Wrists before treatment. 
Fig. I.

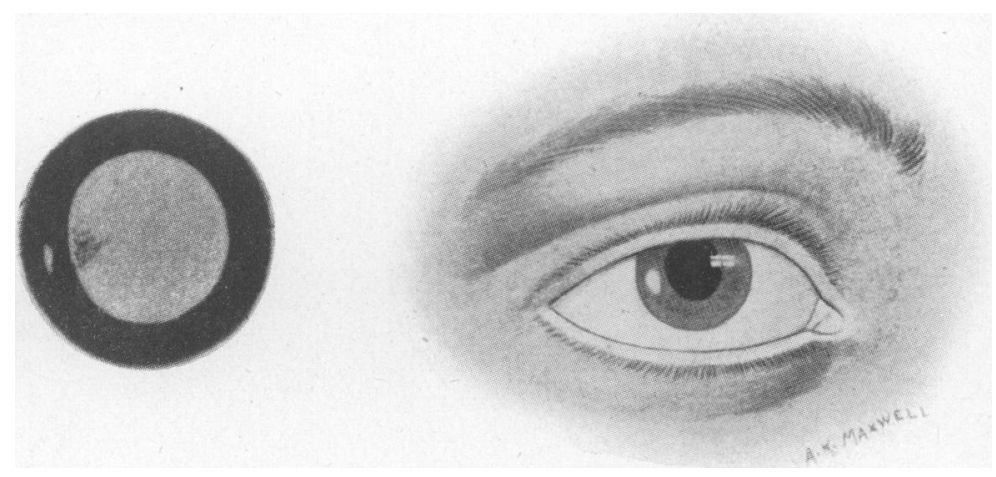

FIG. 2.

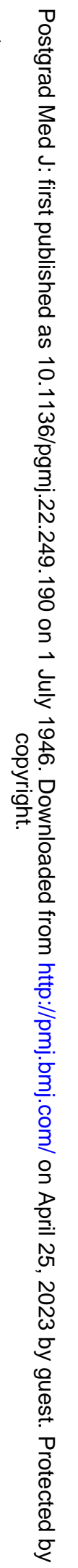

